\title{
Aproximación al Control de Convencionalidad desde la jurisprudencia brasileña
}

\author{
Abordagem de Controle de Convencionalidade a partir da \\ jurisprudência brasileira
}

\author{
Guilherme Vitor de Gonzaga Camilo ${ }^{1}$ \\ Pablo César Rosales Zamora ${ }^{2}$
}

\begin{abstract}
RESUMEM
La presente investigación tiene como objetivo presentar el desarrollo y aplicación del control de convencionalidad, destacando su papel como instrumento de fortalecimiento y efectividad del Derecho Internacional de los Derechos Humanos. El control de convencionalidad es una herramienta desarrollada en el marco del Sistema Interamericano de Derechos Humanos, basado en la Convención Americana sobre Derechos Humanos. El objetivo de la investigación es demostrar cómo esta herramienta ha sido desarrollada a través del Sistema Interamericano de Derechos Humanos y cómo ha ocurrido su aplicación tanto por la Corte Interamericana de Derechos Humanos como por los tribunales brasileños. Se concluye que, a pesar de los esfuerzos de la Corte Interamericana para desarroll ar la herramienta mencionada, los avances en su aplicación a nivel nacional han sido lentos.
\end{abstract}

\section{PALABRAS CLAVES:}

Derechos humanos, Derecho Internacional, Control de convencionalidad.

\begin{abstract}
This paper aims to present the development and application of Conventionality control, highlighting its role as an instrument for strengthening and enforcement of international law and human rights. Conventionality Control is a tool developed within the framework of the Inter-American Human Rights System, based on the American Convention on Human Rights. The purpose of the paper is to demonstrate how this tool was developed through the InterAmerican System of Human Rights and as has been its implementation by both the InterAmerican Court of Human Rights as the Brazilian courts. It is concluded that, despite the efforts of the Inter-American Court to develop the aforementioned tool, progress in its application at the national level has been slow.
\end{abstract}

\section{KEYWORDS:}

Human rights, International Law, Conventionality Control.

\footnotetext{
1 Analista do Ministério Público de São Paulo. Mestre em Direito Internacional pela Pontifícia Universidade Católica de Minas Gerais (Bolsista Capes). Especialista em Direito Internacional pelo Centro de Direito Internacional.

${ }^{2}$ Maestre en Derecho Internacional. Asesor legal en la Oficina de Derecho Internacional Públic o del Ministerio de Relaciones Exteriores de la República del Perú. Professor de Derecho Internacional.
} 


\section{INTRODUCCIÓN}

Como se afirma en la doctrina, el Derecho aplicable en los ordenamientos internos va más allá del conjunto de normas que se producen en el ámbito nacional ${ }^{3}$. En este contexto, no basta con examinar la norma cuya fuente procede del ordenamiento jurídico interno, sino que se torna necesario analizar la aplicación y plasmación de las fuentes del Derecho Internacional en el orden jurídico interno.

El elenco de fuentes del Derecho Internacional se puede desprender, aunque no exhaustivamente, del artículo 38.1 del Estatuto de la Corte Internacional de Justicia ${ }^{4}$. Es preciso entender que de estas fuentes “(...) emanam direitos e deveres das pessoas internacionais configurando os modos formais de constatação do direito internacional. " 5

De todas las fuentes mencionadas en el Estatuto, cabe destacar la del artículo 38.1.a, los tratados, los cuales son concebidos por la Convención de Viena sobre el Derecho de los Tratados de 1969 (en adelante, la CVDT) como “(...) un acuerdo internacional celebrado por escrito entre Estados y regido por el derecho internacional, ya conste en un instrumento único o en dos o más instrumentos conexos y cualquiera que sea su denominación particular" ${ }^{6}$.

\footnotetext{
${ }^{3}$ COMBACAU, Jean y SUR, Serge. Droit International Public. Paris : Montchrestien, 2008, pp. $181-182$. Como señalan ambos autores respecto al Derecho internacional : « De plus en plus toutefois ces règles, surtout les règles conventionnelles et les actes qui en sont dérivés, sont appelés à produire des effets in ternes, c'est-à-dire à créer por les particuliers des droits et des obligations qu'ils puissent directement invoquer ».

4 " 1 . La Corte, cuya función es decidir conforme al derecho internacional las controversias que le sean sometidas, deberá aplicar:

a. las convenciones internacionales, sean generales o particulares, que establecen reglas ex presamente reconocidas por los Estados litigantes;

b. la costumbre internacional como prueba de una práctica generalmente aceptada como derecho;

c. los principios generales de derecho reconocidos por las naciones civilizadas;

d. las decisiones judiciales y las doctrinas de los publicistas de mayor competencia de las distintas naciones, como medio auxiliar para la determinación de las reglas de derecho, sin perjuicio de lo dispuesto en el Artículo 59 (...)". 5 ACCIOLY, Hildebrando; CASELLA, Paulo Borba; SILVA, G. E. do Nascimento. Manual de Direito Internacional Público, 20 ed. São Paulo: Saraiva, 2011, p. 146.

${ }^{6}$ Artículo 2.1.a de la Convención de Viena sobre el Derecho de los Tratados de 1969. Ver una definición similar pero para las relaciones con las organizaciones internacionales en el artículo2.1 a de la Convención de Viena sobre el Derecho de los Tratados entreEstados y Organizaciones Internacionales o en tre Organizaciones Internacionales.
} 
Por su creciente importancia en el Derecho Internacional, se abordará en es te trabajo la relevancia de la aplicación de los tratados en el orden jurídico interno brasileño a través del estudio del mecanismo conocido como "control de convencionalidad"7.

Considerando la relevancia que el Derecho Internacional posee actualmente, especialmente la jurisprudencia de la Corte Interamericana de Derechos Humanos (en adelante, la Corte IDH) y la CVDT, no se puede comprender que el Derecho Internacional y el Derecho Interno carezcan de relación entre sí, pues este entendimiento no se condice con la realidad actual $^{8}$. De esta forma, la implementación del Derecho Internacional en Estados como la República Federativa del Brasil (en adelante, Brasil o el Estado brasileño) se torna en una actividad jurisdiccional de primer orden. De acuerdo con Paulo Borba Casella,

\begin{abstract}
Não mais se pode invocar a dicotomia entre as duas ordens, que levou a alguns "enganos" e "desvios de rumo" cometidos no passado. Doravante, superados.

Aceito o princípio, resta assegurar a sua implementação, de modo que se passe a aplicar como tal na jurisprudência, e na administração do estado brasileiro, soberano e independente, mas integrado ao mundo e neste inserto, com todas as consequências daí decorrentes, e que não mais podem ser ignoradas, ou tratadas como emanação da boa vontade nacional, em relação ao exterior ${ }^{9}$.
\end{abstract}

En este contexto, surge el control de convencionalidad, que es un mecanismo que introduce la Corte IDH y que refleja la inclinación del Sistema Interamericano de Derechos Humanos (en adelante, SIDH) por conseguir que las obligaciones asumidas internacionalmente por los Estados sean cumplidas, independientemente de la configuración de su ordenamiento interno, y a través del cual los tratados en materia de derechos humanos sirven como filtro a la aplicación del Derecho Interno. Esto significa que una norma interna puede dejar de ser empleada para que el texto de la Convención Americana sobre Derechos Humanos (en adelante, $\mathrm{CADH})$, o de otros tratados interamericanos, sea aplicado.

Este artículo tiene como objetivo demostrar el surgimiento y construcción del Control de Convencionalidad, su aplicación por la Corte Interamericana y por los tribunales brasileños, verificando el progreso actual en la aplicación de la referida doctrina.

\footnotetext{
${ }^{7}$ Para un panorama del desarrollo de la jurisprudencia interamericana sobre el control de convencionalidad, ver SALMÓN, Elizabeth. El 'control de convencionalidad' y su impacto en el diálogo entre los tribunales nacionales y la Corte Interamericana de Derechos Humanos. En: NOVAKOVIC, Marko (Ed.). Basic concepts of Public International Law - Monism \& Dualism, Universidad de Belgrado, 2013, pp. 524 - 546. ${ }^{8}$ ACCIOLY, Hildebrando; CASELLA, Paulo Borba; SILVA, G. E. do Nascimento. Op. Cit, p. 27.

${ }^{9}$ ACCIOLY, Hildebrando; CASELLA, Paulo Borba; SILVA, G. E. do Nascimento. Op. Cit, p. 27.
} 


\section{LA APLICACIÓN DE LOS TRATADOS EN BRASIL}

Para comprender el control de convencionalidad en Brasil es necesario, inicialmente, entender cómo se aplican los tratados en este orden jurídico interno, teniendo en cuenta que el citado mecanismo se basa en el cumplimiento de las obligaciones establecidas en los tratados del SIDH.

Uno de los puntos iniciales del análisis en cuanto a la aplicación de los tratados en el ordenamiento nacional brasileño se refiere al estatus concedido internamente a estos instrumentos.

El Supremo Tribunal Federal (en adelante, STF) de Brasil mantuvo por mucho tiempo el entendimiento de que todos los tratados, independientemente de la materia sobre la cual versasen, deben ser considerados como parte del Derecho Interno.

Sobre la jerarquía de los tratados en el ordenamiento brasileño, el precedente a destacar anterior a la Constitución Federal de $1988^{10}$ es el Recurso Extraordinario N. ${ }^{\circ} 80.004$ de 1977 en que se les otorgó un estatus equivalente a una ley ordinaria, sin otorgar un estatus diferente a los tratados de derechos humanos. El referido proceso trató sobre la aplicación del Convenio que establece una Ley Uniforme de Ginebra sobre letras de cambio y pagarés ${ }^{11}$. Según el tribunal brasileño, pese a que el tratado no tenía aplicabilidad en el derecho interno brasileño, no se podrían sobreponer las leyes emitidas en el país.

De este modo, la solución de conflictos entre los tratados y las normas de origen interno estaba basada en el criterio cronológico (lex posterior derogat priori) o de especialidad (lex specialis derogat generalis). Ejemplo de este último es el caso de la detención por deudas, prohibida de manera general por la $\mathrm{CADH}^{12}$, pero que el STF lo subordinó al texto constitucional brasileño toda vez que su artículo 5, inciso LXVII, permite la prisión de los depositarios infieles. En este caso, relativo al Habeas Corpus N. ${ }^{\circ}$ 72131, el STF comparó la

\footnotetext{
${ }^{10}$ Actualmente, es la constitución en vigencia en la República Federativa del Brasil.

${ }^{11}$ Aprobado el 7 de junio de 1930.

12 Ver el artículo 7 inciso 7 de la CADH que señala que "Nadie será detenido por deudas. Este principio no limita los mandatos de autoridad judicial competente dictados por incumplimientos de deberes alimentarios".
} 
constitución brasileña con la constitución argentina, afirmando que, si hubiera sido interés del legislador, habría diferenciado expresamente el estatus de los tratados de derechos humanos ${ }^{13}$.

Como un intento de conciliar la posición del STF con la visión doctrinaria que apuntaba por la constitucionalidad de los tratados de derechos humanos, el entonces ministro Sepúlveda Pertence sustentó, en el Recurso de Habeas Corpus N. ${ }^{\circ}$ 79785-RJ - proceso en que se analizaba el derecho a una doble instancia, garantizada por la $\mathrm{CADH}$, frente al foro privilegiado garantizado a los jueces en el ordenamiento brasileño -, lo siguiente:

[...] aceitara outorga de força supra-legalàs convenções de direitoshumanos, de modo a dar aplicação direta às suas normas - até se necessário, contra a lei ordinária sempre que, sem ferir a Constituição, a complementem, especificando ou ampliando os direitos e garantias dela constantes. ${ }^{14}$

La posición defendida por el ministro solamente obtuvo éxito con la Enmienda Constitucional 45/2004, del 30 de diciembre de 2004. La citada enmienda condicionó la jerarquía constitucional de los tratados de derechos humanos al mecanismo de aprobación de las enmiendas constitucionales, creando dos tipos de tratados de derechos humanos, los aprobados por el quórum para enmienda y los aprobados por el quórum para ley ordinaria, y no mencionó el tratamiento que iba a ser dado a los tratados anteriores.

El estatus de los tratados de derechos humanos fue alterado nuevamente con la decisión proferida por el STF en el RE 466.343 del 2008, en la cual se discutió la legitimidad de la prisión del depositario infiel a la luz del Pacto Internacional de Derechos Civiles y Políticos y de la CADH. En este caso, el banco fiduciario planteaba un recurso contra el acuerdo del Tribunal de Justicia de Río de Enero, que negó la prisión civil al deudor fiduciante en caso de incumplimiento de la obligación de entrega del bien. En este recurso fueron consideradas dos posiciones que elevaron el Derecho Internacional de los Derechos Humanos (en adelante, $\mathrm{DIDH}$ ) a una posición superior, dándole el estatus de Derecho que permite el control de legitimidad de la ley ordinaria.

\footnotetext{
${ }^{13}$ RAMOS, André de Carvalho. Pluralidade das ordens jurídicas: a relação do direito brasileiro com o direito internacional.Curitiba: Juruá, 2012, p.48.

${ }^{14}$ BRASIL. Supremo Tribunal de Federal. Recurso de Habeas Corpus N. ${ }^{\circ}$ 79785-RJ, Relator Sepúlveda Pertence, Plenário, DJ 19.09.2003.
} 
La posición mayoritaria fue aquella defendida por el ministro Gilmar Mendes, que confirió el estatus de supralegalidad a los tratados de derechos humanos, al contrario de la posición defendida por el ministro Celso de Mello que los consideraba con rango constitucional.

Ahora bien, la Constitución Federal ya demostraba su elección por la superioridad de los tratados de derechos humanos, incluso antes de la Enmienda Constitucional 45/2004. Esto se demuestra en la redacción del artículo 5 párrafo 2, que establece lo siguiente:

Os direitos e garantias expressos nesta Constituição não excluem outros decorrentes do regime e dos princípios por ela adotados, ou dos tratados internacionais em que a República Federativa do Brasil seja parte. ${ }^{15}$

En los párrafos 3 y 4 del referido artículo, incluidos con la Enmienda Constitucional 45/2004, también se expresa esta predilección:

$\S 3^{\circ}$ Os tratados e convenções internacionais sobre direitos humanos que forem aprovados, em cada Casa do Congresso Nacional, em dois turnos, por três quintos dos votos dos respectivos membros, serão equivalentes às emendas constitucionais.

$\S 4^{\circ} \mathrm{O}$ Brasil se submete à jurisdição de Tribunal Penal Internacional a cuja criação tenha manifestado adesão. ${ }^{16}$

De esta forma, también lo entendió el ministro Gilmar Mendes, como se desprende del texto siguiente:

Ressalte-se, nesse sentido, que há disposições da Constituição de 1988 que remetem o intérprete para realidades normativas relativamente diferenciadas em face da concepção tradicional do direito internacional público.

Refiro-me, especificamente, a quatro disposições que sinalizam para uma maior abertura constitucional ao direito internacional e, na visão de alguns, ao direito supranacional. A primeira cláusula consta do parágrafo único do art. $4^{\circ}$, que estabelece que a "República Federativa do Brasil buscará a integração econômica, política, social e cultural dos povos da América Latina, visando à formação de uma comunidade latino-americana de nações".

Em comentário a este artigo, o saudoso Professor Celso Bastos ensinava que tal dispositivo constitucional representa uma clara opção do constituinte pela integração do Brasil em organismos supranacionais.

A segunda cláusula é aquela constante do $\S 2^{\circ}$ do art. $5^{\circ}$, ao estabelecer que os direitos e garantias expressos na Constituição brasileira "não excluem outros decorrentes do regime e dos princípios por ela adotados, ou dos tratados internacionais em que a República Federativa do Brasil seja parte".

A terceira e quarta cláusulas foram acrescentadas pela Emenda Constitucional $n^{\circ} 45$, de 08.12.2004, constantes dos $\S \S 3^{\circ}$ e $4^{\circ}$ do art. $5^{\circ}$, que rezam, respectivamente, que "os tratados e convenções internacionais sobre direitos humanos que forem aprovados, em cada Casa do Congresso Nacional, em dois turnos, por três quintos dos votos dos respectivos membros, serão equivalentes às emendas constitucionais", e "o

${ }^{15}$ BRASIL. Constituição da República Federativa do Brasil de $\mathbf{1 9 8 8 .}$

Revista Juris Poiesis, Rio de Janeiro. v. 23, n. 32, p. 550-573, 2020. ISSN 2448-0517. 
Brasil se submete à jurisdição de Tribunal Penal Internacional a cuja criação tenha manifestado adesão. ${ }^{17}$

Como se observa de la cita, la predilección del legislador constitucional por los derechos humanos obedece a una tendencia mundial, siendo observada también en aquel tiempo en el continente americano por Argentina, Paraguay y Uruguay. De este modo, la consagración constitucional de los derechos humanos constituyó la forma de darles mayor efectividad y aproximar el Derecho Interno al Derecho Internacional.

La tesis vencedora en el referido recurso fue conforme al voto del ministro Gilmar Mendes, garantizándose así el rango supralegal a los tratados de derechos humanos aprobados fuera de las reglas del párrafo 3 del artículo 5 de la Constitución de 1988. Y es que la Carta Magna no habría garantizado el estatus constitucional de estos tratados en las disposiciones del párrafo 2 del mencionado artículo, pero al mismo tiempo les estaba concediendo un tratamiento especial.

Con la consideración del estatus supralegal a los tratados de derechos humanos, siguiendo lo establecido por la Enmienda Constitucional 45/2004, se consolida la posibilidad de realizarse el control de convencionalidad sobre las normas internas por los tribunales nacionales.

\section{LA CONSTRUCCIÓN DEL CONTROL DE CONVENCIONALIDAD}

Según Bernardo Fernandes, el control de convencionalidad es una forma de compatibilizar las normas del Derecho Interno y los tratados de derechos humanos ratificados por un Estado y en vigor. Se trataría de un control de validez de aquellas normas, teniendo como parámetro a aquellos ${ }^{18}$. Asimismo, el control de convencionalidad serviría justamente como

\footnotetext{
${ }^{17}$ BRASIL. Supremo Tribunal de Federal. Recurso Extraordinário N. ${ }^{\circ}$ 466343-1 SP, Relator César Peluso, Voto do Min. Gilmar Mendes, DJ 05.06.2009.

${ }^{18}$ FERNANDES, Bernardo Gonçalves. Curso de Direito Constitucional, 6a. Ed. Salvador: Juspodium, 2014, p. 1227.
} 
mecanismo de implementación del Derecho Internacional en el orden jurídico interno, sin que su empleo deje de constituir un gran desafío para los jueces domésticos en pleno siglo XXI ${ }^{19}$.

La compatibilidad del ordenamiento jurídico pasa a ser no solamente conforme a la Constitución (brasileña) de 1988, sino que gana un nuevo parámetro de adecuación, las normas de derechos humanos adoptadas en el ámbito internacional, siendo esta el ámbito del que partiría el control vertical de las normas jurídicas. En este sentido, Luiz Guilherme Marinoni al afirmar lo siguiente:

\footnotetext{
Vale dizer que a legislação infraconstitucional, para produzir efeitos, não deve apenas estar em consonância com a Constituição Federal, mas também com os tratados de direitos humanos. Nesta perspectiva, existem dois parâmetros de controle e dois programas de validação do direito ordinário. Além da Constituição, o direito supralegal está a condicionar e a controlar a validade da lei.

Isto significa que a lei, nesta dimensão, está submetida a novos limites materiais, postos nos direitos humanos albergados nos tratados internacionais, o que revela que o Estado contemporâneo - que se relaciona, em recíproca colaboração, com outros Estados constitucionais inseridos numa comunidade -, tem capacidade de controlar a legitimidade da lei em face dos direitos humanos tutelados no país e na comunidade latino-americana. ${ }^{20}$
}

Pese a que el origen histórico del control de convencionalidad sea objeto de desacuerdos, la doctrina sustenta que tuvo su inicio en el sistema francés y data del inicio de la década de 1970 a través de la Decisión N. ${ }^{\circ}$ 74-54DC, de enero de 1975, en que el Consejo Constitucional Francés se declaró incompetente para analizar la convencionalidad preventiva de las leyes, por el hecho de no tratarse de un control de constitucionalidad propiamente dicho ${ }^{21}$.

En nuestra región, el control de convencionalidad empieza a adquirir importancia en la región cuando es introducido en el plano del SIDH a partir de algunas sentencias de la Corte $\mathrm{IDH}$, tribunal que viene realizando el examen del Derecho estatal a partir de la CADH. Destaca en este punto los casos Myrna Mack Chang vs. Guatemala ${ }^{22}$ y Almonacid Arellano vs. Chile ${ }^{23}$.

\footnotetext{
${ }^{19}$ ACCIOLY, Hildebrando; CASELLA, Paulo Borba; SILVA, G. E. do Nascimento. Op. Cit, p. 125.

20 MARINONI, Luiz Guilherme; MITIDIERO, Daniel; SARLET, Ingo Wolfgang. Curso de Direito Constitucional. São Paulo: Editora Revista dos Tribunais, 2012, p. 1187.

${ }^{21}$ MAZZUOLI, Valerio de Oliveira. O controle jurisdicional da convencionalidade das leis, $3^{\text {a }}$. Ed. São Paulo: Editora Revista dos Tribunais, 2013, p.88.

${ }^{22}$ Corte IDH. Caso Myrna Mack Chang Vs. Guatemala. Fondo, Reparaciones y Costas. Sentencia de 25 de noviembre de 2003. Serie C No. 101.

${ }^{23}$ Corte IDH. Caso Almonacid Arellano y otros Vs. Chile. Excepciones Preliminares, Fondo, Reparaciones y Costas. Sentencia de 26 de septiembre de 2006. Serie C No. 154.
} 
En el primer caso se utilizó la expresión "control de convencionalidad” en el voto del juez Sergio García Ramírez ${ }^{24}$. Según el referido magistrado, la expresión citada caracteriza el papel de la Corte IDH de adecuar los actos de los Estados al orden internacional:

En cierto sentido, la tarea de la Corte se asemeja a la que realizan los tribunales constitucionales. Estos examinan los actos impugnados --disposiciones de alcance general--a la luz de las normas, los principios y los valores de las leyes fundamentales. La Corte Interamericana, por su parte, analiza los actos que llegan a su conocimiento en relación con normas, principios y valores de los tratados en los que funda su competencia contenciosa. Dicho de otra manera, si los tribunales constitucionales controlan la "constitucionalidad", el tribunal internacional de derechos humanos resuelve acerca de la "convencionalidad" de esos actos. A través del control de constitucionalidad, los órganos internos procuran conformar la actividad del poder público --y, eventualmente, de otros agentes sociales -- al orden que entraña el Estado de Derecho en una sociedad democrática. El tribunal interamericano, por su parte, pretende conformar esa actividad al orden internacional acogido en la convención fundadora de la jurisdicción interamericana y aceptado por los Estados partes en ejercicio de su soberanía. ${ }^{25}$

En un caso posterior, también bajo la presidencia del juez Sergio Ramírez, el pleno de la Corte IDH utilizó por primera vez la expresión “control de convencionalidad” al enunciar la obligación de los jueces nacionales de aplicar las leyes nacionales conforme a la CADH, del modo siguiente:

La Corte es consciente que los jueces y tribunales internos están sujetos al imperio de la ley y, por ello, están obligados a aplicar las disposiciones vigentes en el ordenamiento jurídico. Pero cuando un Estado ha ratificado un tratado internacional como la Convención Americana, sus jueces, como parte del aparato del Estado, también están sometidos a ella, lo que les obliga a velar porque los efectos de las disposiciones de la Convención no se vean mermadas por la aplicación de leyes contrarias a su objeto y fin, y que desde un inicio carecen de efectos jurídicos. En otras palabras, el Poder Judicial debe ejercer una especie de "control de convencionalidad" entre las normas jurídicas in ternas que aplican en los casos concretos y la Convención Americana sobre Derechos Humanos. En esta tarea, el Poder Judicial debe tener en cuenta no solamente el tratado, sino también la interpretación que del mismo hahecho la Corte Interamericana, intérprete última de la Convención Americana. ${ }^{26}$

En principio, el control de convencionalidad lo realizan propiamente los tribunales regionales de derechos humanos. Esto ocurre para evitar que el Estado sea, al mismo tiempo, juez y parte ${ }^{27}$, tomando en consideración que este es quien ha participado en la creación del

\footnotetext{
${ }^{24}$ MARTINS, Leonardo; MOREIRA, Thiago Oliveira. Constitucionalidade e Convencionalidade de Atos do Poder Público: concorrência ou hierarquia? Um contributo em face da situação jurídico constitucional brasileira. En: Anuario de Derecho Constitucional Latinoamericano, AÑO XVII, Montevideo, 2011, p. 471.

${ }^{25}$ Corte IDH. Caso Myrna Mack Chang Vs. Guatemala. Fondo, Reparaciones y Costas. Sentencia de 25 de noviembre de 2003. Serie C No. 101.

${ }^{26}$ Corte IDH. Caso Almonacid Arellano y otros Vs. Chile. Excepciones Preliminares, Fondo, Reparaciones y Costas. Sentencia de 26 de septiembre de 2006. Serie C No. 154.

${ }^{27}$ RAMOS, André de Carvalho. Op. Cit. p.57.
} 
tratado y está llamado, al mismo tiempo, a su aplicación. Pero, como se percibe en el caso Almonacid Arellano vs. Chile, ese control realizado por la Corte IDH experimentó una expansión con el argumento de que los propios magistrados internos de un país estarían sometidos a las disposiciones de la CADH. Por lo tanto, bajo el entendimiento de la Corte IDH, se superó el entendido que el control de convencionalidad debía limitar al juez internacional y se pasó a admitir que este control podría ser realizado mediante un ejercicio de compatibilización efectuado por los propios jueces nacionales ${ }^{28}$.

Ahora bien, como asevera André de Carvalho Ramos, el control de convencionalidad realizado por el juez nacional es preliminar o provisorio, pues incluso si lo concretizara, no vincularía al juez internacional $^{29}$. De esta forma, todo órgano jurisdiccional internacional estaría apto para realizar el control de convencionalidad de modo definitivo. Si bien existe la necesidad de ser trabajado como cuestión preliminar, esto no impide que el tribunal internacional declare de oficio la "inconvencionalidad" de la ley o el acto del poder público ${ }^{30}$. Como señala la Corte IDH en la sentencia del caso Trabajadores Cesados Del Congreso (Aguado Alfaro y otros) vs. Perú:

En otras palabras, los órganos del Poder Judicial deben ejercer no sólo un control de constitucionalidad, sino también "de convencionalidad" ex officio entre las normas internas y la Convención Americana, evidentemente en el marco de sus respectivas competencias y de las regulaciones procesales correspondientes. Esta función no debe quedar limitada exclusivamente por las manifestaciones o actos de los accionantes en cada caso concreto, aunque tampoco implica que ese control deba ejercerse siempre, sin considerar otros presupuestos formales y materiales de admisibilidad y procedencia de ese tipo de acciones ${ }^{31}$.

Adicionalmente, cabe destacar que el control de convencionalidad busca conservar el efecto útil de la CADH. Esto fue defendido por la Corte IDH en la sentencia citada, en la que afirma que:

Cuando un Estado ha ratificado un tratado internacional como la Convención Americana, sus jueces también están sometidos a ella, lo que les obliga a velar porque el efecto útil de la Convención no se vea mermado o anulado por la aplicación de leyes contrarias a sus disposiciones, objeto y fin. En otras palabras, los órganos del Poder Judicial deben ejercer no sólo un control de constitucionalidad, sino también "de convencionalidad" ex officio entre las normas internas y la Convención Americana, evidentemente en el marco de sus respectivas competencias y de las

\footnotetext{
${ }^{28}$ FERNANDES, Bernardo Gonçalves. Op. Cit, p.1228.

${ }^{29}$ RAMOS, André de Carvalho. Op. Cit. p.58.

${ }^{30}$ FERNANDES, Bernardo Gonçalves. Op. Cit, p.1229.

31 Corte IDH. Caso Trabajadores Cesados del Congreso (Aguado Alfaro y otros). Vs. Perú. Solicitud de Interpretación de la Sentencia de Excepciones Preliminares, Fondo, Reparaciones y Costas. Sentencia de 30 de Noviembre de 2007 Serie C No. 174.
} 
regulaciones procesales correspondientes. Esta función no debe quedar limitada exclusivamente por las manifestaciones o actos de los accionantes en cada caso concreto, aunque tampoco implica que ese control deba ejercerse siempre, sin considerar otros presupuestos formales y materiales de admisibilidad y procedencia de ese tipo de acciones ${ }^{32}$.

Se puede considerar a esta modalidad del control de convencionalidad como una especie de control difuso, justamente por implicar que todos los jueces nacionales la aplican. Contrasta así con el control de convencionalidad "concentrado", realizado por la Corte IDH, que solo lo realiza este tribunal. Según el juez Eduardo Mac-Gregor, el control de convencionalidad difuso transforma al juez nacional en una especie de juez interamericano, de forma que este se torna en un guardián de la $\mathrm{CADH}$ y de los tratados interamericanos de derechos humanos y de la jurisprudencia de la Corte $\mathrm{IDH}^{33}$. De ahí se desprende la idea de un "bloque de convencionalidad", pues, como se puede notar, la adecuación de los actos y leyes internas debe ser conforme al conjunto de compromisos establecidos por el Estado en materia de derechos humanos. Como señala la Corte IDH,

\begin{abstract}
En la especie, al referirse a un "control de convencionalidad" la Corte Interamericana ha tenido a la vista la aplicabilidad y aplicación de la Conven ción Americana sobre Derechos Humanos, Pacto de San José. Sin embargo, la misma función se despliega, por idénticas razones, en lo que toca a otros instrumentos de igual naturaleza, integrantes del corpus juris convencional de los derechos humanos de los que es parte el Estado: Protocolo de San Salvador, Protocolo relativo a la Abolición de la Pena de Muerte, Convención para Prevenir y Sancionar la Tortura, Convención de Belém do Pará para la Erradicación de la Violencia contra la Mujer, Convención sobre Desaparición Forzada, etcétera. De lo que se trata es de que haya conformidad entre los actos internos y los compromisos internacionales contraídos por el Estado, que generan para éste determinados deberes y reconocen a los individuos ciertos derechos. ${ }^{34}$
\end{abstract}

Por otra parte, como esclarece Martins y Moreira, al realizar el control concentrado, la Corte IDH no revoca la ley “inconvencional” o crea una norma para cuidar de aquella relación llevada a la Corte, sino que apenas declara la "inconvencionalidad" y determina que el Estado adecue su legislación a los compromisos asumidos en materia de derechos humanos, bajo pena

\footnotetext{
32 Corte IDH. Caso Trabajadores Cesados del Congreso (Aguado Alfaro y otros). Vs. Perú. Solicitud de Interpretación de la Sentencia de Excepciones Preliminares, Fondo, Reparaciones y Costas. Sentencia de 30 de Noviembre de 2007 Serie C No. 174.

${ }^{33}$ MAG-GREGOR, Eduardo. Interpretación conforme y control difuso de convencionalidad el nuevo paradigma para el juez mexicano. En: MARINONI, Luiz Guilherme; MAZZUOLI, Valerio de Oliveira (Org.). Controle de Convencionalidade: um panorama latino-americano: Brasil, Argentina, Chile, México, Peru, Uruguai. Brasília, DF: Gazeta Jurídica, 2013, p. 594.

${ }^{34}$ Corte IDH. Caso Trabajadores Cesados del Congreso (Aguado Alfaro y otros). Vs. Perú. Solicitud de Interpretación de la Sentencia de Excepciones Preliminares, Fondo, Reparaciones y Costas. Sentencia de 30 de Noviembre de 2007 Serie C No. 174.
} 
de responsabilidad internacional ${ }^{35}$. Para entender este efecto conviene reflexionar sobre la interacción de dos categorías propias de la teoría general del Derecho, como son la vigencia y la validez de la norma.

$\mathrm{Al}$ respecto, la perspectiva del Estado constitucional y humanista de Derecho rechaza la idea de validez de la ley por la simple vigencia, como defendía la concepción kelseniana, no pudiendo confundirse ambos conceptos. Según Ferrajoli, la vigencia se relaciona a los requisitos formales de la norma, mientras que la validez correspondería a la compatibilidad con el aspecto sustancial de las demás normas ${ }^{36}$. De esta forma, las normas que se ligan a la producción legislativa no solo son formales, sino también sustanciales, como el respeto a los derechos humanos.

La ley puede así ser vigente sin ser válida, pero no válida sin ser vigente. Solamente la norma que fuera vigente y válida será eficaz. Del mismo modo, se ha pronunciado Valerio Mazzuoli en los siguientes términos:

\begin{abstract}
Apenas havendo compatibilidade vertical material com ambas as normas - a Constituição e os tratados - é que a norma infraconstitucional em questão será vigente e válida (e, consequentemente, eficaz). Caso contrário, não passando a lei pelo exame da compatibilidade vertical material com os tratados (segunda análise de compatibilidade), a mesma não terá qualquer validade (e eficácia) no plano do direito interno brasileiro, devendo ser rechaçada pelo juiz no caso concreto. ${ }^{37}$
\end{abstract}

En el mismo sentido, señalaba Miguel Reale lo siguiente:

[...] que todas as fontes operam no quadro de validade traçado pela Constituição de cada país, e já agora nos limites permitidos por certos valores jurídicos transnacionais, universalmente reconhecidos como invariantes jurídico axiológicas, como a Declaração Universal dos Direitos do Homem ${ }^{38}$.

De este modo, tanto los tratados (de derechos humanos) como la Constitución sirven como límites verticales y sustanciales a la producción normativa. Se configura así el control de constitucionalidad y el de convencionalidad de las normas. Mazzuoli incluso defiende que las

\footnotetext{
${ }^{35}$ MARTINS, Leonardo; MOREIRA, Thiago Oliveira. Constitucionalidade e Convencionalidade de Atos do Poder Público: concorrência ou hierarquia? Um contributo em face da situação jurídico constitucional brasileira. En: Anuario de Derecho Constitucional Latinoamericano, AÑOXVII, Montevideo, 2011,pp.463 -483. ${ }^{36}$ FERRAJOLI, Luigi. Derechos y garantías: la ley del más débil. Citado por MAZZUOLI, Valério de Oliveira. Teoria Geral do Controle de Convencionalidade no Direito Brasileiro. En: Revista da Associação dos Juízes do Rio Grande do Sul, ano XXXVI, nº 113, 2009, p. 337.

${ }^{37}$ MAZZUOLI, Valerio de Oliveira. Op. Cit., 2009, p. 341.

${ }^{38}$ REALE, Miguel. Fontes e modelos do direito: para um novo paradigma hermenêutico. São Paulo: Saraiva, 1994, p. 13. Citado por MAZZUOLI, Valério de Oliveira, Op. Cit., 2009, p. 342.
} 
normas supralegales sirven también como límite ${ }^{39}$. Conforme a la idea de supralegalidad de los tratados de derechos humanos, una ley anterior a un tratado, conflictiva con este, sería automáticamente revocada al tiempo de entrada en vigor de este último. Siendo la ley posterior al tratado, esta sería vigente, pero no válida, debiendo ser aplicado el control de convencionalidad.

Con el propósito de precisar el estatus de los tratados de derechos humanos aprobados anteriormente a la Enmienda Constitucional 45/2004, se desarrolló por la doctrina, la teoría que apuntaba a considerarlos materialmente constitucionales, bien como aquellos aprobados después de la referida enmienda, con base en el artículo 5 párrafo 2 de la Constitución de 1988. Los tratados que siguiesen el mecanismo de aprobación del artículo 5 párrafo 3 serían además no solo materialmente, sino también formalmente constitucionales. De esta forma, solo estos últimos no estarían sujetos a denuncia, tomando en cuenta que son cláusulas pétreas ${ }^{40}$.

De acuerdo con Eduardo Appio, a pesar de que autores de gran importancia sobre el tema sustentan que las disposiciones internacionales que tratan sobre derechos humanos deban ser consideradas como parte de la Constitución en sentido material, pero subordinadas a la adopción del procedimiento especial preconizado por la Enmienda 45/2004, el STF ya habría resuelto el problema al haber fijado que solamente por el procedimiento del artículo 5 párrafo 3 , tales disposiciones tendrían el estatus constitucional ${ }^{41}$.

Este hecho no implica la reducción en importancia de los tratados para Brasil, pues este se encuentra potencialmente sujeto a las sanciones a ser impuestas por los tribunales internacionales, en caso de incumplimiento de sus obligaciones internacionales. En efecto, la responsabilidad internacional del Estado brasileño no debe confundirse con los mecanismos internos de incorporación y aplicación de estos tratados, porque se mueven en planos diferentes.

Con la ratificación de la CVDT por Brasil, surge incluso una nueva base para la aplicación nacional del control de convencionalidad. Esta convención, en especial su artículo $27^{42}$, garantiza la aplicación del Derecho Internacional en el orden jurídico interno, contexto en

\footnotetext{
${ }^{39}$ MAZZUOLI, Valerio de Oliveira. Op. Cit, 2009, p. 345.

${ }^{40}$ RAMOS, André de Carvalho. Op. Cit. p.50.

${ }^{41}$ APPIO, Eduardo. Os juízes e o Controle de Convencionalidade no Brasil. In MARINONI, Luiz Guilherme; MAZZUOLI, Valerio de Oliveira(Org.). Op. Cit., p.184.

${ }^{42} \mathrm{El}$ texto de este artículo señala lo siguiente: "Una parte no podrá invocar las disposiciones de su derecho interno como justificación del incumplimiento de un tratado. Esta norma se entenderá sin perjuicio de lo dispuesto en el
} 
el cual se inserta y desenvuelve el control de convencionalidad. Así ya se manifestó la Corte IDH sobre las disposiciones de la CVDT, del modo siguiente:

Como ya ha señalado esta Corte y lo disponeel artículo 27 de la Convención de Viena sobre el Derechode los Tratados de 1969, los Estados no pueden, por razones de orden interno, incumplir obligaciones internacionales. Las obligaciones convencionales de los Estados Parte vinculan a todos sus poderes y órganos, los cuales deben garantizar el cumplimiento de las disposiciones convencionales y sus efectos propios (effet utile) en el plano de su derecho interno. ${ }^{43}$

De acuerdo con Paulo Macedo, las disposiciones del artículo 27 citado obligan al Estado a garantizar la aplicación de los tratados por los órganos internos ${ }^{44}$, esto porque los países deben cumplir las disposiciones asumidas a través de los tratados con base en la buena fe y el principio de pacta sunt servanda. De este modo, la CVDT también sirve como justificación para considerar a los tratados como filtro de validez de las normas internas.

Por otra parte, el control de convencionalidad no solo ha generado la inaplicación de ciertas normas internas, sino que ha propiciado la formulación de nuevas normas, lo cual revela una modificación en la relación entre los Estados y el Derecho Internacional, con incidencia directa de este último sobre los primeros. En este sentido, el control de convencionalidad tiene un doble efecto: por una parte, uno clásico, que se puede llamar de inaplicación; y, por otra parte, uno moderno, que se puede denominar de creación de normas conformes al Derecho Internacional.

Respecto al primer efecto, cabe destacar el caso argentino, cuya Corte Suprema de Justicia, en más de una oportunidad, se ha inclinado favorablemente por la aplicación del control de convencionalidad difuso. Este es, por ejemplo, el caso Mazzeo, Julio Lilo y otros, en la sentencia emitida el 13 de julio de 2007:

Que por su parte, la Corte Interamericana ha señalado que "es consciente que los
jueces y tribunales internos están sujetos al imperio de La ley y, por ello, están
obligados a aplicar las disposiciones vigentes en el ordenamiento jurídico. Pero
cuando un Estado ha ratificado un tratado internacional como La Convención
Americana, sus jueces, como parte del aparato del Estado, también están sometidos a
ella, lo que les obliga a velar porque los efectos de las disposiciones de La Convención

artículo 46." Para una mejor profundización del mismo, se recomienda la lectura de VILLIGER, Mark. Commentary on the 1969 Vienna Convention on the Law of Treaties. Leiden/Boston: Martinus Nijhoff Publishers, 2009, pp. $369-375$.

43 Corte IDH. Caso Gomes Lund y otros ("Guerrilha do Araguaia") Vs. Brasil. Excepciones Preliminares, Fondo, Reparaciones y Costas. Sentencia de 24 de noviembre de 2010. Serie C No. 219, párrafo

${ }^{44}$ MACEDO, Paulo. Comentários ao artigo 27. En: SALIBA, Aziz Tuffi (org.). Direito dos tratados: comentários à Convenção de Viena sobre o direito dos tratados (1969). Belo Horizonte: Arraes Editores, 2011, p. 191. 
no se vean mermados por La aplicación de leyes contrarias a su objeto y fin, y que desde su inicio carecen de efectos jurídicos. En otras palabras, el Poder Judicial debe ejercer una especie de "control de convencionalidad" entre las normas jurídicas internas que aplican en los casos concretos y la Convención Americana sobre Derechos Humanos. En esa tarea, el Poder Judicial debe tener en cuenta no solamente el tratado sino también la interpretación que del mismo ha hecho la Corte Interamericana, intérprete última de la Convención Americana (Serie C No 154, caso “Almonacid”, del 26 septiembre de 2006, parágrafo 124). ${ }^{45}$

En relación al segundo efecto, tómese como ejemplo a los Estados Unidos Mexicanos, el cual realizó alteraciones a su Constitución, promulgadas en julio de 2011, con objeto de abarcar expresamente el control de convencionalidad difuso. Después de los cambios legislativos, la Constitución Mexicana recogió el siguiente texto en su artículo 1:

En los Estados Unidos Mexicanos todas las personas gozarán de los derechos humanos reconocidos en esta Constitución y en los tratados internacionales de los que el Estado Mexicano sea parte, así como de las garantías para su protección, cuyo ejerciciono podrárestringirse ni suspenderse, salvo en los casos y bajolas condiciones que esta Constitución establece.

Las normas relativas a los derechos humanos se interpretarán de conformidad con esta Constitución y con los tratados internacionales de la materia favoreciendo en todo tiempo a las personas la protección más amplia.

Todas las autoridades, en el ámbito de sus competencias, tienen la obligación de promover, respetar, proteger y garantizar los derechos humanos de conformidad con los principios de universalidad, interdependencia, indivisibilidad y progresividad. En consecuencia, el Estado deberá prevenir, investigar, sancionar y reparar las violaciones a los derechos humanos, en los términos que establezca la ley. ${ }^{46}$

Con estas disposiciones, México se adecúa a la posición de la Corte IDH, garantizando legislativamente la observancia de los tratados de derechos humanos y consecuentemente el control de convencionalidad difuso, a ser realizado por todos los jueces nacionales. Este cambio legislativo permite la comparación con la situación presentada por Brasil, sirviendo como punto de partida a los cuestionamientos acerca de su aplicación.

Como se desprende, el control de convencionalidad es esencial para la adecuación de los actos normativos nacionales a las disposiciones de la $\mathrm{CADH}$, debiendo incluso ser encarado como una forma de garantizar la aplicación de los derechos humanos por Brasil y los otros Estados parte de la CADH.

\footnotetext{
45 ARgEnTINA. Corte Suprema de Justicia. Mazzeo, Julio Lilo y otros s/ rec. de casación e inconstitucionalidad. Sentencia de 13 de julio de 2007. Disponible en: < http://www.csjn.gov.ar/jurisp/jsp/fallos.do?usecase=mostrarDocumento\&falloId=1951>. Último acceso: 04 de abril de 2020.

46 MÉXICO. Constitución Política de los Estados Unidos Mexicanos de 1917. Disponible en: <http://www.ordenjuridico.gob.mx/Constitucion/cn16.pdf>. Último acceso: 04 de abril de 2020.
} 


\title{
4. LA APLICACIÓN DEL CONTROL DE CONVENCIONALIDAD POR LOS JUECES BRASILEÑOS
}

En cuanto a su aplicación por los jueces brasileños, el control de convencionalidad aún da sus primeros pasos; sin embargo, las decisiones que mencionan o aplican este mecanismo se han multiplicado. Puede citarse como ejemplo al Habeas Corpus N. ${ }^{\circ} 1.358 .323-2$, emitido por el Tribunal de Justicia del Estado del Paraná, que utilizó la CADH y el control de convencionalidad para pronunciarse acerca de la necesidad de audiencia de custodia en el proceso penal brasileño. Véase, en ese sentido, lo siguiente:

\begin{abstract}
(...) 1. Dispõe o artigo $7^{\circ}$, item 5, da Convenção Americana de Direitos Humanos que "Toda pessoa detida ou retida deve ser conduzida, sem demora, à presença de um juiz ou outra autoridade autorizada pela lei a exercer funções judiciais (...)”. No mesmo sentido assegura o artigo $9^{\circ}$, item 3, do Pacto Internacional de Direitos Civis e Políticos que "Qualquer pessoa presa ou encarcerada em Documento assinado digitalmente, conforme MP n. ${ }^{\circ} 2.200-2 / 2001$, Lei n. ${ }^{\circ} 11.419 / 2006$ e Resolução n. ${ }^{\circ}$ 09/2008, do TJPR/OE O documento pode ser acessado no endereço eletrônico http://www.tjpr.jus.br Página 2 de 20 Habeas Corpus Crime $n^{\circ}$ 1.358.323-2 fls. 2 virtude de infração penal deverá ser conduzida, sem demora, à presença do juiz ou de outra autoridade habilitada por lei a exercer funções judiciais (...)". 2. "Isto porque os direitos humanos são extraídos dos tratados de direitos humanos ratificados pelo Brasil, e, por isso, não se exige da jurisdição apenas um controle de constitucionalidade, com vistas a efetivar os direitos previs tos na Constituição, mas também um controle de convencionalidade, com o objetivo de efetivar os direitos humanos previstos na ordem internacional". 3. "Nesse contexto, o controle de convencionalidade das leis pela jurisdição contribui para que os direitos humanos previstos nos tratados internacionais sejam incorporados às decisões judiciais, permitindo a interiorização deste consenso por meio das decisões judiciais. Deste modo, a jurisdição constitucional funciona como instrumento potencializador da efetividade dos direitos humanos, na medida em que, a partir da compreensão crítica da realidade, sob o prisma direitos humanos, aplica este consenso no âmbito interno, operando, assim, como ferramenta de transformação social $(. . .)^{47}$.
\end{abstract}

Como se observa en la referida decisión, el control de convencionalidad permitió al tribunal interpretar las normas internas de forma que fuese realizada la audiencia de custodia conforme a lo prevista en la CADH.

\footnotetext{
${ }^{47}$ BRASIL. Tribunal de Justiça do Paraná. Habeas Corpus N. ${ }^{\mathbf{0}}$ 1.358.323-2, $3^{\text {a }}$ Vara Criminal do Foro Central da Comarca da Região Metropolitana de Curitiba, Curitiba, PR, DJ 23.04.2015. Disponível em: <https://www.tjpr.jus.br/documents/18319/5218101/Processo_N\%C2\%BA_1358323-2_-_HC_Crime.pdf>. Última acceso: 04 de abril de 2020.
} 
Otra decisión de gran repercusión por la justicia brasileña fue la sentencia emitida en la acción penal N. ${ }^{\circ}$ 0067370-64.2012.8.24.0023 del distrito judicial de Florianópolis, TJSC ${ }^{48}$, en que el magistrado, basándose en la Declaración de Principios sobre la Libertad de Expresión ${ }^{49}$ y en el control de convencionalidad, dejó de aplicar el artículo del Código Penal Brasileño, que trata sobre el desacato del funcionario público.

Cabe mencionar que la Corte Interamericana ya ha expresado su opinión sobre la incompatibilidad del delito de desacato con las disposiciones del artículo 13 de la CADH en el caso llamado "Palamara Iribarne Vs. Chile"50. Actualmente, los tribunales superiores brasileños entienden que el desprecio sigue siendo un delito, en desacuerdo con la interpretación dada por la Corte Interamericana de Derechos Humanos y la Comisión Interamericana de Derechos Humanos. Cabe señalar que en el caso mencionado anteriormente, la Corte Interamericana determinó que Chile debería adaptar su legislación interna a las disposiciones de la CADH con respecto al desprecio y la libertad de expresión.

De acuerdo al juez del referido caso, la Declaración de Principios sobre la Libertad de Expresión establece en su párrafo 11 que "las leyes de desacato atentan contra la libertad de expresión y el derecho a la información". De la misma forma tales leyes atentarían contra el artículo 13 de la $\mathrm{CADH}^{51}$. De ese modo, el magistrado dejó de aplicar el artículo 331 del Código Penal brasileño basado en sendos instrumentos internacionales.

\footnotetext{
${ }^{48}$ BRASIL. Tribunal de Justiça de Santa Catarina. Ação Penal no 0067370-64.2012.8.24.0023, $4^{\mathbf{a}}$ Vara Criminal da Comarca de Florianópolis, Florianópolis, SC, DJ 17.03.2015.

${ }^{49}$ Disponible en: <https://www.cidh.oas.org/basicos/basicos $13 . \mathrm{htm}>$

${ }^{50}$ CORTE INTERAMERICANA DE DERECHOS HUMANOS. Caso Palamara Iribarne vs. Chile. Fondo Reparaciones y Costas. Sentencia de 22 de noviembre de 2005.

${ }^{51}$ El texto del artículo 13 es el siguiente: "1. Toda persona tiene derecho a la libertad de pensamiento y de expresión. Este derecho comprende la libertad de buscar, recibir y difundir informaciones e ideas de todaíndole, sin consideración de fronteras, ya sea oralmente, por escrito o en forma impresa o artística, o por cualquier otro procedimiento de su elección.

2. El ejercicio del derecho previsto en el inciso precedente no puede estar sujeto a previa censura sino a responsabilidades ulteriores, las que deben estar expresamente fijadas por la ley y ser necesarias para asegurar:

a) el respeto a los derechos o a la reputación de los demás, o

b) la protección de la seguridad nacional, el orden público o la salud o la moral públicas.

3. No se puede restringir el derecho de expresión por vías o medios indirectos, tales como el abuso de controles oficiales o particulares de papel para periódicos, de frecuencias radioeléctricas, o de enseres y aparatos usados en la difusión de información o por cualesquiera otros medios encaminados a impedir la comunicación y la circulación de ideas y opiniones.

4. Los espectáculos públicos pueden ser sometidos por la ley a censura previa con el exclusivo objeto de regular el acceso a ellos para la protección moral de la infancia y la adolescencia, sin perjuicio de lo establecido en el inciso 2.
} 
Por otro lado, debe destacarse que Brasil no ha cumplido enteramente las decisiones proferidas por la Corte IDH basadas en el control de convencionalidad. En el caso Gomes Lund y otros (Guerrilla de Araguaya), que trata sobre la ley de amnistía brasileña, la Corte IDH decidió que Brasil debería determinar las responsabilidades penales y aplicar las sanciones y consecuencias previstas por el Derecho Penal, adecuando para eso su Derecho Interno en lo que fuese preciso, en confrontación directa con la Ley de Amnistía N. ${ }^{\circ}$ 6.683/79. Eso significaría, consecuentemente, anular la aplicación de la referida ley.

Brasil, por su parte, instauró la Comisión Nacional de la Verdad con el intento de aplicar el fallo de la Corte. Entretanto, la Ley que instituye la Comisión (Ley N. ${ }^{\circ}$ 12528/11), en su artículo 4 párrafo 4 establece que esta no tiene "carácter jurisdiccional o persecutorio", dejando de lado lo dispuesto en la sentencia de la Corte IDH.

En esa línea, en su resolución de cumplimiento de la sentencia, la Corte IDH declaró, en el año 2014, que Brasil no estaba cumpliendo con investigar los crímenes practicados durante la dictadura militar y que la Ley de Amnistía no podía continuar siendo un obstáculo, como se presentaba para ese momento ${ }^{52}$.

La Corte Interamericana tenía la misma posición en el juicio del caso Vladimir Herzog vs. Brasil, sin embargo, la ley de amnistía sigue vigente, lo que demuestra que no hubo un cumplimiento efectivo de las determinaciones de la Corte IDH y la implementación de la Justicia Transicional.

Se identifica, por ese motivo, que la aplicación del control de convencionalidad ha evolucionado a pasos lentos en la jurisdicción interna brasileña, sin que ello signifique que este

5. Estará prohibida por la ley toda propaganda en favor de la guerra y toda apología del odio nacional, racial o religioso que constituyan incitaciones a la violencia o cualquier otra acción ilegal similar contra cualquier persona o grupo de personas, por ningún motivo, inclusive los de raza, color, religión, idioma u origen nacional." ${ }^{52}$ Corte IDH. Caso Gomes Lund y otros ("Guerrilha do Araguaia") Vs. Brasil. Supervisión de Cumplimiento de Sentencia. Resolución de la Corte Interamericana de Derechos Humanos de 17 de octubre de 2014, párrafo 23. En este punto, la Corte indicalo siguiente: En razón de todo lo expuesto, la Corte concluye que la medidade reparación relativa a la obligación de investigar los hechos del presente caso se encuentra pendiente de cumplimiento. Por ello, el Tribunal requiere que en su próximo informe el Estado presente información actualizada y detallada sobre: i) el estado en el que se encuentran las acciones penales iniciadas en relación con los hechos ocurridos respecto de seis de las víctimas del presente caso, así como si se han iniciado nuevas acciones penales al respecto; ii) las razones por las cuales no se estarían investigando los hechos violatorios en perjuicio de las demás víctimas de este caso, y iii) los esfuerzos que estaría emprendiendo el Estado para garantizar que la interpretación y aplicación de la Ley de Amnistía, la prescripción y la falta de tipificación del delito de desaparición forzada no continúen siendo un obstáculo para el cumplimiento de lo ordenado por la Corte en el presente caso." 
mecanismo deje de aparecer como herramienta utilizada por los tribunales domésticos de este país.

\section{CONCLUSIONES}

La relación entre el Derecho Interno y el Derecho Internacional ha sufrido modificaciones a lo largo del tiempo, con una evolución encaminada hacia el fortalecimiento de las normas internacionales. La aplicación efectiva de los tratados y el estatus que estos ganaron en el Derecho brasileño ilustra bien este desarrollo.

La presencia de la CVDT y del control de convencionalidad permite identificar con más facilidad que las relaciones entre el Derecho Internacional y el Derecho Interno no puedan ser más vistas como si se tratase de dos sistemas diferentes que apenas interactúen.

En este contexto, queda claramente establecido el papel del control de convencionalidad. Su construcción histórica en el SIDH es un testimonio claro del papel que el Derecho Internacional - y más específicamente, el DIDH - ha alcanzado en el contexto actual. La doctrina y jurisprudencia interamericana respalda el control de convencionalidad en cuanto parte del sistema estatal, como comprueban el creciente número de casos en control de convencionalidad difuso.

En el SIDH, el control de convencionalidad se ha forjado como un aspecto indispensable en el Estado de Derecho, dado que en este contexto no puede más apoyarse la idea de tratados de derechos humanos que sean incumplidos, dado que el Derecho Internacional ha brindado medios para que se cumplan las obligaciones internacionales que de ellos se desprenden. El papel del control de convencionalidad es, por tanto, justamente el de servir como instrumento para un real cumplimiento de tratados de derechos humanos, garantizando que sea efectivizada la protección del ser humano. 
Internamente, la posición brasileña frente a los tratados de derechos humanos se alteró con el fortalecimiento del Derecho Internacional, al considerarlos como poseedores de un estatus supra-legal o constitucional.

Brasil, a pesar de contar aún con pocas decisiones de tribunales domésticos en que se ha utilizado el control de convencionalidad, ha demostrado que este es un instrumento que tiene la potencialidad de alcanzar una mayor efectividad en el sistema nacional. Otros países que participan del SIDH, como México y Argentina, también demuestran modificaciones en su legislación para abarcar este mecanismo.

Por último, a lo que Brasil y otros Estados de la región deben aspirar con el control de convencionalidad es que sea más conocido por su estructura jurisdiccional y ejercido de forma difusa, con el intento de hacer valer las obligaciones asumidas internacionalmente por este Estado, así como dar efectividad a los derechos humanos de la población, bajo pena de imputársele responsabilidad internacional.

\section{BIBLIOGRAFÍA}

ACCIOLY, Hildebrando; CASELLA, Paulo Borba; SILVA, G. E. do Nascimento. Manual de Direito Internacional Público, 20 ed. São Paulo: Saraiva, 2011.

ARGENTINA. Corte Suprema de Justicia. Mazzeo, Julio Lilo y otros s/ rec. de casación e inconstitucionalidad. Sentença de 13 de julio de 2007. Disponível em: < http://www.csjn.gov.ar/jurisp/jsp/fallos.do? usecase=mostrarDocumento\&falloId=1951>.

Último acceso: 04 de abril de 2020.

BINDER, Christina. The prohibition of amnesties by the inter-american court of human rights. German Law Jornal, v 12, n. 5, 2010, p. 1203-1230. Disponível em: <http://www.corteidh.or.cr/tablas/r26381.pdf>. Último acceso em: 04 de abril de 2020.

BRASIL. Código de Processo Civil. Brasília, DF, 2015.

BRASIL. Constituição da República Federativa do Brasil de 1988. Brasília, DF, 1988.

BRASIL. Decreto $n^{\circ}$ 6.949, de 25 de agosto de 2009. Promulga a Convenção Internacional sobre os Direitos das Pessoas com Deficiência e seu Protocolo Facultativo, assinados em Nova York, em 30 de marzo de 2007. Brasília, DF, 26 agosto 2009.

BRASIL. Supremo Tribunal de Federal. Habeas Corpus 72131-RJ. Relator: Ministro Marco Aurélio, Plenário, Brasília, DF, DJ 23 nov.1995. 
Supremo Tribunal de Federal. Recurso em Habeas Corpus 79785-RJ, Relator Sepúlveda Pertence, Plenário, DJ 19 set.2003.

Supremo Tribunal de Federal. Recurso Extraordinário 466343-1 SP. Relator: Ministro César Peluso, Plenário, Brasília, DF, DJ 03 de diciembre de. 2008. Disponível em: < http://redir.stf.jus.br/paginadorpub/paginador.jsp?docTP=AC\&docID=595444>. Último acceso: 04 de abril de 2020.

Supremo Tribunal Federal. Recurso Extraordinário n. 80.004-SE. Relator: Ministro Xavier de Albuquerque, Plenário, Brasília, DF, DJ, 1 de jun. de 1977. Disponível em: < http://redir.stf.jus.br/paginadorpub/paginador.jsp?docTP=AC\&docID=175365>. $\quad$ Último acceso: 04 de abril de 2020.

. Supremo Tribunal de Federal. Recurso Extraordinário 466343-1 SP, Relator César Peluso, Voto do Min. Gilmar Mendes, DJ 05 jun. 2009.

BRASIL. Tribunal de Justiça do Rio de Enero. Processo ${ }^{\circ}$ 0013156-07.2015.8.19.0008. $2^{\mathrm{a}}$ Vara Criminal da Comarca de Beldford Roxo, Beldford Roxo, RJ, DJ 04.07.2016. Disponível em: < http://emporiododireito.com.br/juiz-do-tjrj-faz-controle-de-convencionalidade-docrime-de-desacato/>. Último acceso: 05 agosto 2020.

Tribunal de Justiça de Santa Catarina. Ação Penal no 0067370-64.2012.8.24.0023, $4^{\text {a }}$ Vara Criminal da Comarca de Florianópolis, Florianópolis, SC, DJ 17 mar. 2015.

. Tribunal de Justiça do Paraná. Habeas Corpus No 1.358.323-2, $3^{\text {a }}$ Vara Criminal do Foro Central da Comarca da Região Metropolitana de Curitiba, Curitiba, SC, DJ 23 abril 2015. Disponível em: < https://www.tjpr.jus.br/documents/18319/5218101/Processo_N\%C2\%BA_1358323-2__HC_Crime.pdf>. Última visita: 04 de abril de 2020.

CARVALHO, Alexander Perazo Nunes de. Convencionalização do direito civil: a aplicação dos tratados e convenções internacionais no âmbito das relações privadas. Revista de Direito Internacional, v. $12, \quad$ n. 2, 2015, p. 342-354. Disponível em: < http://www.publicacoesacademicas.uniceub.br/index.php/rdi/article/view/3756/pdf >. Último acceso: 04 de abril de 2020.

CORTE INTERAMERICANA DE DERECHOS HUMANOS. Advisory Opinion OC-21/14. Opinião Consultiva de 19 agosto 2014.

. Caso Almonacid Arellano y otros Vs. Chile. Fondo, Reparaciones y Costas. Sentença de 26 de septiembre de 2006, série c, nº 154.

Caso Barrios Altos Vs. Perú. Sentença de 14 de marzo de 2001.

. Caso "La Última Tentación de Cristo" (Olmedo Bustos y otros) Vs. Chile. Fondo, Reparaciones y Costas. Sentença de 5 de febrero de 2001, série c, no 73.

2006.

. Caso La Cantuta Vs. Perú. Fondo, Reparaciones y Costas. Sentença de 29 de nov. 
2011.

. Caso Gelman vs. Uruguay. Fondo, Reparaciones. Sentença de 24 de febrero de

Caso Gomes Lund e Outros ("Guerrilha do Araguaia") vs. Brasil. Sentença de 24 de noviembre de 2010. série c, $\mathrm{n}^{\mathrm{o}} 101$.

. Caso Myrna Mack Chang Vs. Guatemala. Sentença de 25 de noviembre de 2003,

Caso Palamara Iribarne vs. Chile. Fondo Reparaciones y Costas. Sentença de 22 de noviembre de 2005.

Caso Tibi Vs. Ecuador. Sentença de 07 de septiembre de 2004.

Caso Trabajadores Cesados del Congreso (Aguado Alfaro y otros) Vs. Perú. Fondo, Reparaciones y Costas. Sentença de 24 de noviembre de 2006, série c, nº 158.

Supervisão de Cumprimento de Sentença Caso Gomes Lund e Outros ("Guerrilha do Araguaia") vs. Brasil. Resolução de 17 de octubre de 2014.

DULITZKY, Ariel E. An Inter-American Constitutional Court? The invention of the Conventionality Control by the Inter-American Court of Human Rights. Texas International Law Journal, vol. 50, 2015, p. 45-93. Disponível em: <http://www.conseilconstitutionnel.fr/conseil-constitutionnel/root/bank/download/7454DCa7454dc.pdf >. Último acceso: 04 de abril de 2020.

FERNANDES, Bernardo Gonçalves. Curso de Direito Constitucional, 6 ed. Salvador: Juspodium, 2014.

FRANÇA. Conselho Constitucional Francês. Decision 74-54 DC, Voluntary Interruption of Pregnancy Act. Decisão de 15 jan. 1975. Disponível em: <http://www.conseilconstitutionnel.fr/conseil-constitutionnel/root/bank/download/7454DCa7454dc.pdf>. Último acceso: 04 de abril de 2020.

Constituição da Quinta República de 1958. Disponível em: <http://www.conseilconstitutionnel.fr/conseil-

constitutionnel/root/bank_mm/portugais/constitution_portugais.pdf $>$. Último acceso: $04 \mathrm{de}$ abril de 2020.

LARRIEUX, Jorge T. Caso Gelman vs. Uruguay. Justicia transicional, Corte Interamericana de Derechos Humanos y el control de convencionalidad. Anuário de Derecho Constitucional Latinoamericano, ano XIX, 2013, p. 589-606. Disponível em: < http://www.juridicas.unam.mx/publica/librev/rev/dconstla/cont/2013/pr/pr33.pdf>. Último acceso: 04 de abril de 2020.

MACEDO, Paulo. Comentários ao artigo 27. In SALIBA, Aziz Tuffi (org.). Direito dos tratados: comentários à Convenção de Viena sobre o direito dos tratados (1969). Belo Horizonte: Arraes Editores, 2011, p.191-197. 
MAC-GREGOR ,Eduardo Ferrer, Conventionality Control: The New Doctrine of the InterAmerican Court of Human Rights, American Journal of International Law Unbound, 93, 2015, p.93-99. Disponível em: <https://www.asil.org/sites/default/files/Ferrer\%20MacGregor\%2C\%20Conventionality\%20Controlv3.pdf>. Último acceso: 04 de abril de 2020.

Interpretación conforme y control difuso de convencionalidad el nuevo paradigma para el juez mexicano. In MARINONI, Luiz Guilherme; MAZZUOLI, Valério de Oliveira (Org.). Controle de Convencionalidade: um panorama latino-americano: Brasil, Argentina, Chile, México, Peru, Uruguai. Brasília, DF: Gazeta Jurídica, 2013, p.547-596.

MAC-GREGOR, Eduardo Ferrer. DOMÍNGUEZ, Pablo González. Death Penalty, Amnesty Laws, and Forced Disappearances: Three Main Topics of the InterAmerican Corpus Juris in Criminal Law. Notre Dame Journal of International \& Comparative Law: Vol. 5: Iss. 1, Article 4, p.63-113. Disponível em: <http://scholarship.law.nd.edu/cgi/viewcontent.cgi?article=1029\&context=ndjicl $>$. Último acceso: 04 de abril de 2020.

MARINONI, Luiz Guilherme et al. Novo Código de Processo Civil Comentado. São Paulo: Revista dos Tribunais, 2015.

MARINONI, Luiz Guilherme; MITIDIERO, Daniel; SARLET, Ingo Wolfgang. Curso de Direito Constitucional. São Paulo: Editora Revista dos Tribunais, 2012.

MARTINS, Leonardo; MOREIRA, Thiago Oliveira. Constitucionalidade e Convencionalidade de Atos do Poder Público: concorrência ou hierarquia? Um contributo em face da situação jurídico constitucional brasileira. Anuario de Derecho Constitucional Latinoamericano, AÑO XVII, Montevideo, 2011, pp. 463-483.

MAZZUOLI, Valério de Oliveira. O controle jurisdicional da convencionalidade das leis, 3. ed. ver., atual. e ampl. São Paulo: Editora Revista dos Tribunais, 2013.

. Teoria Geral do Controle de Convencionalidade no Direito Brasileiro. Revista da Associação dos Juízes do Rio Grande do Sul, ano XXXVI, nº 113, 2009, p. 333-370.

Teoria Geral do Controle de Convencionalidade no Direito Brasileiro. In MARINONI, Luiz Guilherme; MAZZUOLI, Valério de Oliveira (Org.). Controle de Convencionalidade: um panorama latino-americano: Brasil, Argentina, Chile, México, Peru, Uruguai. Brasília, DF: Gazeta Jurídica, 2013, p.3-56.

MÉXICO. Constitución Política de los Estados Unidos Mexicanos de 1917. Disponível em: <http://www.ordenjuridico.gob.mx/Constitucion/cn16.pdf>. Último acceso: 04 de abril de 2020.

NEGISHI, Yota. The Pro Homine Principle's role in regulating the relationship between Conventionality Control and Constitutionality Control. Max Plank Institute for Comparative Public Law and International Law (MPIL) Research Paper Series, n.13, 2016, p. 1-27. Disponível em: <http://papers.ssrn.com/sol3/papers.cfm?abstract_id=2791008>. Último acceso: 04 de abril de 2020. 
ORGANIZAÇÃO DAS NAÇÕES UNIDAS. Convenção de Viena sobre o Direito dos Tratados. Viena, 23 maio 1969. Disponível em: < https://treaties.un.org/doc/publication/unts/volume\%201155/volume-1155-i-18232english.pdf>. Último acceso: 04 de abril de 2020.

Estatuto da Corte Internacional de Justiça. 1945. Disponível em:< http://www.direitoshumanos.usp.br/index.php/Corte-Internacional-deJusti\%C3\%A7a/estatuto-da-corte-internacional-de-justica.html>. Último acceso: 04 de abril de 2020.

ORGANIZAÇÃO DOS ESTADOS AMERICANOS. Convenção Americana sobre Direitos Humanos (Pacto de San José da Costa Rica). San José, 1969. Disponível em: < https://www.cidh.oas.org/basicos/portugues/c.convencao_americana.htm>. Último acceso: 04 de abril de 2020 .

RAMOS, André de Carvalho. Pluralidade das ordens jurídicas: a relação do direito brasileiro com o direito internacional.Curitiba: Juruá, 2012.

SÁGUES, Nestor Pedro. El "control de convencionlad" em el sistema interamericano, y sus anticipos em el âmbito de los derechos econômico-sociales. Concordancias y diferencias com el sistema europeo. Instituto de Investigaciones Juridicas, 2012, p.381-417. Disponível em: <http://www.ijf.cjf.gob.mx/cursosesp/2012/derhumancontrolconvencionalidad/Nestor\%20Sag ues.pdf>. Último acceso em: 04 de abril de 2020.

Data de Submissão: 17/04/2020

Data de Aceite: 18/05/2020 